\title{
Design e os artefatos do Século XXI: evidências de uma nova cultura do desejo
}

Design and artifacts of the 21st century: evidence of a new culture of desire

BELCHIOR, Camilo; Mestre; Universidade do Estado de Minas Gerais

camilo.belchior@uemg.br

REZENDE, Edson José Carpintero; Doutor; Universidade do Estado de Minas Gerais

edson.carpintero@uemg.br

\section{Resumo}

A proposta deste artigo é fazer um breve levantamento histórico passando por momentos da história do design e por conceitos utilizados na área, que poderão nos dar diretrizes para refletir sobre a criação de objetos de desejo. Da simplicidade surgida na década de 40, passando pela revolução da Apple, a cultura do desejo e o processo de transformação dos artefatos, pretendemos compreender como surgiu esta nova cultura do desejo neste início de século XXI e como poderia impactar no processo projetual.

Palavras Chave: Design; Artefato; Desejo.

\section{Abstract}

The purpose of this article is to make a brief historical review through moments of the history of design and concepts used in the field of design that may give us guidelines to reflect on the creation of objects of desire. From the simplicity that emerged in the 1940s, through Apple's revolution, the culture of desire and the process of transforming artifacts, we wanted to understand how this new culture of desire emerged in the early 21st century and how it could impact the design process..

Keywords: Design; Artifact; Desire. 


\section{Introdução}

Buscaremos neste artigo, através de pesquisa bibliográfica e breve levantamento histórico, abordar conceitos utilizados no campo do design que podem dar diretrizes para refletir sobre a criação de objetos de desejo, tais como os conceitos de affordance, prazer, cultura do desejo e a relação com o processo de transformação de coisas em artefatos.

Na década de 40, século XX, surge um novo conceito para o design mundial enraizado na exemplar simplicidade, oriundo das criações de um casal: Charles e Ray Eames (FIG. 1), que usaram de sua paixão pelo design como combustível criativo e que os colocaria definitivamente na história do design mundial. Foram várias as contribuições do casal, mas, provavelmente, a principal foi o estilo completamente novo que criaram para o seguimento da movelaria, que muitos chamam até hoje de "o estilo dos Eames", que associa elegância com modernidade, sofisticação com simplicidade e funcionalidade com ludicidade. Foi este conceito, associado à relação que iniciaram no final dos anos 40 com a indústria de móveis Herman Miller, que deu ao casal a possibilidade de alçar voos mais altos, pois contavam com todo o parque fabril e tecnológico da empresa. Inicialmente foram as cadeiras moldadas em compensado, destaque para a Lounge Chair, depois as cadeiras com fibra de vidro moldado. Mais tarde com o avanço tecnológico a injeção de alumínio possibilitou aos Eames o que seria o auge da sua criação, ou seja, as cadeiras Aluminum Group, produtos com uma incrível leveza visual proporcionado pelo reduzido número de elementos estruturais (o esqueleto da cadeira) que na verdade é a peça principal e mais interessante do produto. A criação desta linha de cadeiras teve uma característica importante para a época: para garantir o completo conforto do usuário, o casal Eames criou uma peça única para o assento, ou seja, uniram o assento e o espaldar em uma única peça com um profundo estudo para a região lombar do corpo humano. Este design foi seguido e copiado por inúmeros profissionais e indústrias de móveis no mundo inteiro. Considera-se a representatividade do casal Eames como uma instituição (marca) simbólica para a cultura do design mundial, além de configurar até os dias atuais como objetos de desejo.

Figura 1 - Casal Eames e a Lounge Chair e cadeira da Aluminum Group

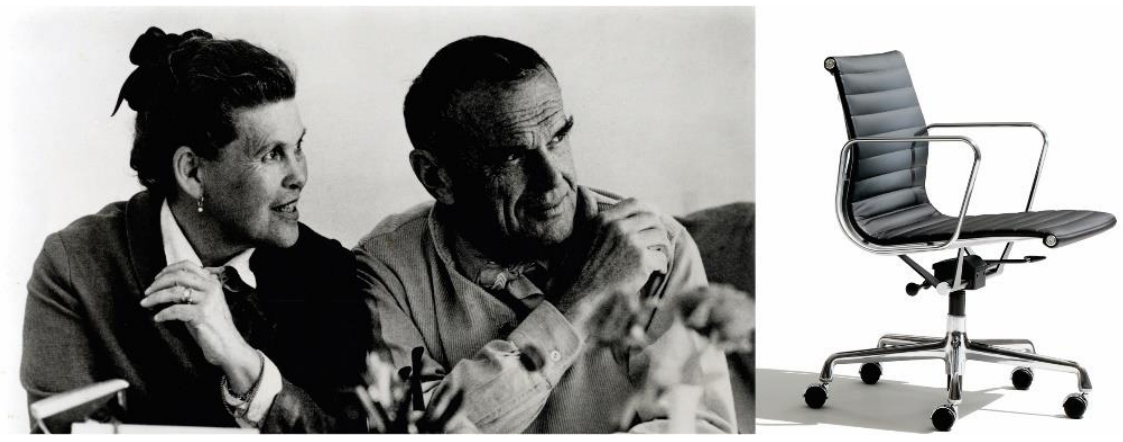

Fonte: https://goo.gl/UcSR1V

Possivelmente, um dos seguidores deste conceito de simplicidade tenha sido a empresa Braun, uma indústria alemã, criada em 1921 que passou por vários processos de desenvolvimento, chegando à criação de diversos produtos em conjunto com professores e alunos da recém-criada Escola de Ulm na Alemanha, (considerada a Bauhaus do período pós Segunda Guerra Mundial). Na década de 60 a Braun atinge o seu momento mais importante, ao dar a direção do departamento 
de design da empresa ao arquiteto e designer Dieter Rams, que foi o designer que influenciou na inovação dos produtos da marca no século XX, tornando-os sucesso no mundo inteiro e referência projetual para outras empresas. Segundo Rams, o segredo para ter alcançado este sucesso estava em priorizar os traços simples no produto e o mais importante, torná-los mais intuitivos, ou seja, dispensar o uso de manuais, minimizando e facilitando a sua usabilidade. Na verdade, constata-se que a receita de Dieter Rams foi usada por várias empresas mais recentes, como a Apple, que alcançou o auge do seu sucesso a partir do lançamento dos produtos iPod e iPhone, que possuem em sua raiz projetual o mesmo conceito dos artefatos intuitivos da Braun.

\section{Simplicidade e affordance}

Ao analisar a etimologia da palavra "intuir" verifica-se que sua origem advém dos sinônimos "perceber, discernir ou pressentir", ou seja, está diretamente relacionada com a percepção humana. A percepção humana é o resultado de uma ideia ou sensação que se tem relacionada a alguma coisa exterior ao corpo humano e que é captada por meio dos sentidos: visão, olfato, paladar, audição, tato. Pesquisadores da área como: Santaella $(1998,2008)$ e Norman (2008), asseguram que a percepção é o primeiro processo cognoscitivo ${ }^{1}$ que permite captar informações sensoriais ao redor do corpo humano, registrá-las na memória e, com o decorrer do tempo, irão se tornar uma espécie de arquivo: o repertório de vida de cada pessoa, que inclui suas experiências pessoais. É por meio da percepção que se consegue formar a ideia de um objeto, pois é através desta percepção que se formaliza significativamente as cores, texturas, odores, formas, sons que, ao serem processados pelo cérebro humano, são relacionadas com o "arquivo da memória" que contém o repertório das percepções adquiridas ao longo de cada existência. Este é o primeiro passo para a construção da significação dos objetos.

Ao ver, ouvir, sentir ou de outra forma perceber o meio ambiente, o sistema afetivo faz o julgamento, alertando outros centros no cérebro e liberando neurotransmissores apropriados para o estado afetivo. $O$ resultado é que tudo o que fazemos tem, ao mesmo tempo, um componente cognitivo e um componente afetivo - cognitivo para atribuir significado, afetivo para atribuir valor. (NORMAN, 2008, p. 45-46).

Quando se fala em artefatos, existe uma diferença crucial em relação aos objetos: os artefatos são objetos modificados pela intencionalidade humana, sendo, portanto, passíveis de conter elementos e características que neste artigo serão chamados de "variáveis" e que podem ser agregadas ao artefato de forma intencional pelo seu criador, ou seja, o designer. Scaletsky corrobora com este pensamento, falando:

Desde os tempos das cavernas, a representação por meio de signos é responsável pela expressão dos sentidos propostos pelos homens na tentativa de representar o mundo em que vivem. Assim, pode-se dizer que os signos compõem um código pelo qual se expressam, uma linguagem, como a formada pelas palavras. A linguagem é um processo coletivo, fundado na cultura, que possibilita ao homem compreender e representar o mundo em que vive, reconhecer-se como humano e relacionar-se com outros indivíduos. Sob esse ponto de vista, é possível dizer que também uma organização é formada por um conjunto de signos - por exemplo, seus produtos e serviços, que remetem a algo exterior a ela, e com a capacidade de provocar infinitas associações de caráter conotativo. Portanto, um automóvel nunca é só um veículo destinado à locomoção de pessoas, pois pode remeter a velocidade, juventude, masculinidade, sucesso e a outras tantas associações possíveis.

\footnotetext{
${ }^{1}$ Que possui aptidão para conhecer; que tem habilidade de conhecer.
} 
(SCALETSKY, 2016, p. 15).

Quando Dieter Rams buscou imbuir os artefatos criados para a Braun com uma simplicidade mais intuitiva, pode-se inferir que ele buscou variáveis, que associadas entre si, gerariam signos que, na percepção humana, tornariam o artefato mais familiar, amistoso, fácil de manipular e usar, considerando que, em algum momento da vida dos usuários dos produtos Braun, provavelmente, tiveram algum tipo de contato com aspectos semelhantes a essas variáveis e, pela experiência adquirida, saberiam como manipular esses artefatos. Um conceito que se relaciona diretamente com a essa premissa é o termo affordance.

O conceito de affordance foi inicialmente utilizado pelo psicólogo James J. Gibson no livro The Ecological Approach to Visual Perception e, mais tarde, no livro The Psychology of Everyday Things de 1988 de Norman (2008) onde foi aperfeiçoado. O autor define o conceito como o aspecto do design de um objeto (artefato) que sugere como o próprio objeto (artefato) deve ser usado, ou seja, affordance refere-se a intuitividade de um objeto ou a sua sugestão de uso. Um pouco mais a frente, Norman (2008) corrigiu seu termo dizendo que o correto seria: perceived affordance, isto porque no design o mais importante é se concentrar no que o público percebe, do que seria a verdade pura. O objetivo do designer é fazer com que o utilizador (usuário) do artefato perceba qual é a ação possível a se fazer com ele. Um exemplo básico deste conceito é o caso da maçaneta. Quando se olha para uma porta qualquer com maçaneta, a única interação que parece possível é a de pegá-la e girar para abrir a porta.

Um dos produtos mais comentados, que deu origem a uma revolução na relação homem/artefato neste início de século XXI, foi o lançamento do primeiro iPod (FIG. 2), criado e produzido pela Apple Inc. e lançado no mercado em 23 de outubro de 2001. Na época, a empresa apresentava ao mundo um tocador de música digital, ultra portátil, que suportaria uma enorme quantidade de músicas digitais, ainda não possível na época, podendo ser transportado dentro do bolso.

Figura 2 - Primeira geração do iPod da Apple 2001

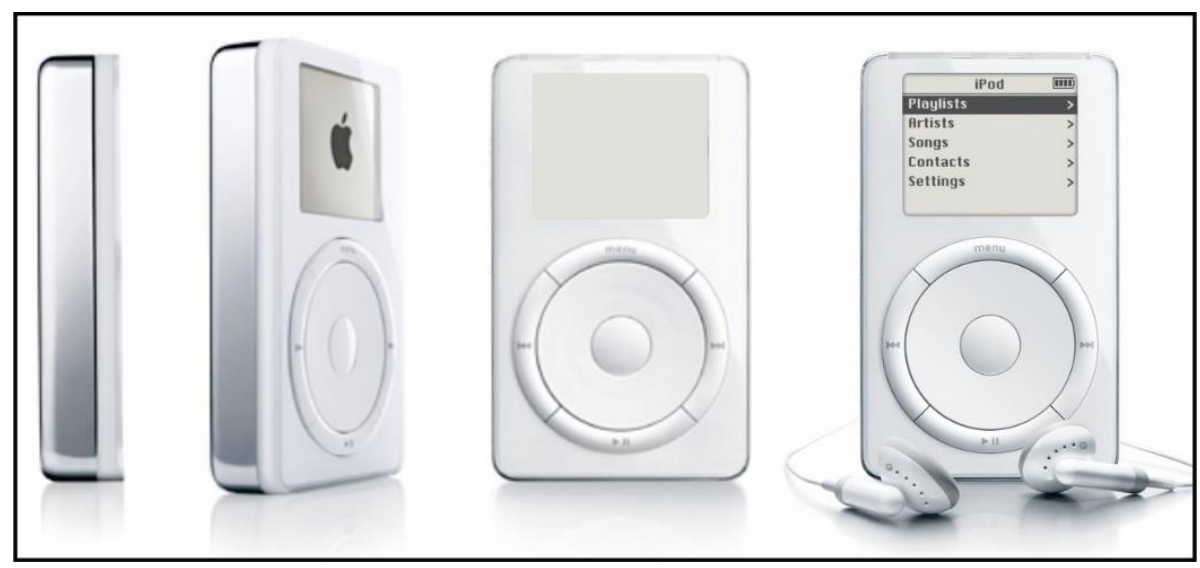

Fonte: https://goo.gl/GEaGT9

Mas a revolução do produto não estava apenas nos melhoramentos técnicos, mas sim na proposta de relação intuitiva com o produto, que possuía apenas um comando central capaz de acionar todas as funções do aparelho. Observa-se o surgimento de uma nova relação entre homem e artefatos. Mozota, Klöpsch e Costa (2011) fazem uma citação em seu livro, sobre uma fala do 
designer Philippe Starck, sobre a necessidade de mudar o paradigma da estética dos artefatos:

\begin{abstract}
A urgência nos dias de hoje não é criar um carro ou uma cadeira mais bonita do que o outro. O belo é um conceito obsoleto agora e não responde à urgência que a sociedade enfrenta hoje, quando a barbárie desponta novamente. O que precisamos fazer é trocar artefatos estéticos por artefatos semânticos, o que resulta na substituição do belo pelo bom. Devemos começar outra vez do zero para que esses objetos e máquinas nos sirvam, de modo que o objeto seja bom para nós, para que vivamos melhor. (MOZOTA; KLÖPSCH; COSTA, 2011, p. 52).
\end{abstract}

Evidencia-se que a cultura de consumo estabelecida pelo design ao longo dos anos, desde o seu entendimento, passou por um processo evolutivo criando uma ponte que vai do tangível ao intangível. Hoje, as características intangíveis dos artefatos são consideradas como um dos principais fatores de diferenciação de um novo produto dentro do mercado de consumo.

O regime hiperindividualista de consumo que se expande é menos estatutário do que experiencial, hedonista, emocional, em outras palavras, estético: o que importa agora é sentir, viver momentos de prazer, de descoberta ou de evasão, não estar em conformidade com códigos de representação social (LIPOVETSKY, 2015, p. 30).

Pode-se refletir que o design do século XXI ultrapassa as questões puramente materiais para atuar fortemente nas possibilidades imateriais, incluindo as variáveis sígnicas, que atuarão sobre as sensações e emoções que estão na camada da subjetividade humana. Esta característica está presente especificamente em um dos princípios básicos do design universal, que compreende que o design deve ser independente das experiências dos usuários, que por via de retorno, apresenta artefatos destituídos de complexidades de uso.

\title{
Design e o prazer
}

Existem algumas necessidades que são básicas, como alimentação, vestuário, transporte, educação etc. Essas necessidades são condições para uma vida minimamente aceitável, sendo que a falta de algum dos elementos básicos causa prejuízos na qualidade de vida. De certa forma podese dizer que as pessoas são programadas para buscar suprir suas necessidades básicas (NORMAN, 2008). No entanto existem outras coisas que ao longo da vida aprende-se a desfrutar e que estão relacionadas com a cultura, costumes, aprendizados, enfim, o repertório de vida das pessoas.

O prazer de saciar uma necessidade básica está em um nível diferente do prazer relacionado à cultura, por exemplo. Jordan (2003), em seu livro Designing Pleasurable Products apresentou um modelo para a classificação dos prazeres, elaborado pelo antropologista canadense Lionel Tiger. Esta classificação apresenta quatro tipos diferentes de prazer: físico, social, psicológico e ideológico.

Os prazeres físicos têm a ver com o corpo e os órgãos sensoriais. Eles incluem os prazeres relacionados ao toque, saber, cheiro e à sensualidade. No caso dos produtos, isso envolve principalmente a sensação tátil no uso desses produtos. O cheiro também afeta a satisfação com o produto (como o cheiro de carro novo). Os prazeres sociais derivam do relacionamento com os outros como, por exemplo, os amados, os amigos e os colegas de trabalho. Também incluem os prazeres resultantes da relação com a sociedade - status e imagem têm um papel importante aqui. Produtos que promovam a integração social como uma cafeteira - ou produtos que mostrem uma distinção - como uma joia ou roupa de marca - geram prazeres sociais. Os prazeres psicológicos estão relacionados às reações cognitivas, mentais e emocionais das pessoas. Esse tipo de prazer é resultante da experiência com produtos e diretrizes nesse sentido são facilidade de aprendizado e 
eficiência. Os prazeres ideológicos referem-se à estética dos produtos e aos valores que ele incorpora. Por exemplo, um produto biodegradável possui o valor de responsabilidade ambiental. A parte associada à estética está ligada à ideia de que os produtos também podem ser uma forma de arte (JORDAN, 2003, p. 182).

Davis (2003) acredita que as transformações globais que ocorrem desde a metade do século $X X$, como a necessidade urgente de equalização da sobrevivência humana na Terra, afetou direta e inconscientemente todas as pessoas, numa busca infinita por experiências e experimentações que trouxessem cada vez mais prazer ou uma sensação de saciedade, mesmo que seja temporária. Lipovetsky (2009) acrescenta dizendo que a sociedade centrada na expansão das necessidades é, antes de tudo, aquela que reordena a população e o consumo de massa sob a lei da obsolescência, da sedução e da diversificação, aquela que faz passar o econômico para a órbita da forma de moda. O autor se refere como "forma de moda" aquela que se manifesta em toda a sua radicalidade na cadência acelerada das mudanças de produtos, na instabilidade e na precariedade das coisas industriais. $\mathrm{O}$ autor afirma que a lógica econômica realmente varreu todo ideal de permanência. É a regra do efêmero que governa a produção e o consumo dos objetos.

Durante muitos anos, os designers e a comunidade relacionada à disciplina debateram exaustivamente sobre o que seria mais importante: a beleza/estética do artefato ou a sua utilidade/função? Atualmente, os criadores de artefatos, buscam fazer as pessoas se apaixonarem por suas criações, que seus objetos ou serviços não apenas satisfaçam uma necessidade, mas tornem-se objetos de desejo. O que pode ter mudado? Para Davis:

A dinâmica do desejo humano foi transformada recentemente. Essa mudança foi nos dominando sem nos apercebermos nem estarmos preparados para ela. [...] Nesta era de transformações, a grande mudança é a redefinição do papel essencial do ser humano na natureza, começando pela realidade mais elementar: o instinto de sobrevivência humana, origem de todos os desejos, medos e entusiasmos. Essa mudança profunda na dinâmica do desejo humano pode marcar a divisão entre a primeira e a segunda parte da história do Homem. O comportamento humano está sendo controlado por uma nova ordem de prazer, um novo desejo fundamental tão poderoso quanto o que trouxe cada um de nós ao mundo (DAVIS, 2003, p. 16).

\section{Cultura do desejo}

Há mais de vinte anos, Davis (2003) está à frente do projeto The Human Desire Project que deu origem ao livro A Nova Cultura do Desejo, cuja finalidade principal foi estudar e entender "por que desejamos as coisas que desejamos e fazemos as coisas que fazemos?" (DAVIS, 2003, p. 15).

\footnotetext{
A maioria de nós não tem a menor ideia do que deseja realmente. Sabemos que desejamos alguma coisa - e a desejamos com ansiedade e paixão, até ferocidade. Mas simplesmente não sabemos exatamente que coisa é essa. Essa incapacidade parece especialmente estranha no momento presente, quando a espécie humana está muito atenta à questão da satisfação, própria e alheia, e quando a lista das coisas que desejamos e precisamos adquirir, fazer, experimentar e alcançar é maior e mais indispensável do que nunca. Nossa cultura nos induz a pensar em nossos desejos a cada minuto do dia: quero isso, isso e isso. Mesmo assim, no fundo de nossas mentes, há sempre uma pontada de angústia, alguma ansiedade enigmática, uma sensação de que aquilo que realmente nos traria satisfação ainda não foi identificado nem inventado. (DAVIS, 2003, p. 15).
}

Davis (2003) acredita que a partir da metade do século XX o mundo passou por uma mudança importante, porém sutil, que alterou a percepção das pessoas acerca do desejo, levando-as a uma 
nova cultura do desejo. Acredita-se que uma boa parcela da sociedade atual consegue discernir claramente a diferença entre necessidades e desejos. As pessoas têm necessidades de comer, vestir, dormir, ter um teto para se abrigar, necessidades fisiológicas, emocionais e físicas.

Para Lacan (1992, p. 269) "o desejo do homem encontra seu sentido no desejo do outro, não tanto porque o outro detenha as chaves do objeto desejado, mas porque seu primeiro objeto é ser reconhecido pelo outro". O desejo é o desejo do outro, pois o desejo é decorrência da relação do Outro com a ordem simbólica.

Necessidades podem suprir uma falta, mas os desejos levam a busca da realização de sonhos que são gradualmente construídos na memória humana, resultado da somatória de suas experiências, vivências e observações da vida. "A dialética não é, portanto, entre função e forma, mas entre função e significado" (VERGANTI, 2012, p. 28).

Durante muitos anos, uma parcela da academia brasileira ensinou a seus alunos que o design, em primeiro lugar, deveria suprir as necessidades das pessoas. Eles não estavam errados, porém, atualmente vive-se uma nova ordem: as necessidades podem e devem ser atendidas, outras necessidades podem ser constantes, mas poderão ser, pelo menos, temporariamente atendidas, já os desejos superam as necessidades, os desejos permanecem, são constantes e intensos, imateriais.

De acordo com Davis (2003), a sociedade está mudando para uma cultura "da cura do estado de espírito", pois a necessidade de benefícios "psicoespirituais" não é somente uma necessidade poderosa do consumidor no momento, passou a ser "a última necessidade significativa que resta no mundo desenvolvido" (p. 252).

Norman (2008) acredita que as pessoas estruturam seus próprios mundos para terem condições de sustentarem suas vidas. Para o autor, os significados e sentimentos especiais que se tem por pessoas, lugares ou coisas, são os vínculos com a sua própria historicidade (passado e futuro). Ele enfatiza que quando alguma coisa dá prazer, quando se torna uma parte da vida das pessoas, e quando a maneira como se interage define o seu lugar na sociedade, então se tem amor.

\footnotetext{
O design faz parte dessa equação, mas a interação pessoal é o segredo. O amor surge por ser conquistado, quando as características especiais de um objeto fazem dele uma parte quotidiana de nossa vida, quando ele intensifica nossa satisfação, quer seja por causa de sua beleza, seu comportamento ou seu componente reflexivo. (NORMAN, 2008, p. 257).
}

É por esta razão que um estudo mais aprofundado acerca do desejo pode levar o design a atingir as reais emoções de seu público e com isto calçar a construção de um vínculo mais estruturado entre homens/artefato, o que levará esta relação a um consumo mais consciente (NORMAN, 2008).

Para Mitchell (1993) o design não foca apenas na projeção de artefatos, mas em projetar as funções, contexto de uso e sistemas de organização, de forma que se abandona o paradigma centrado no produto. $\mathrm{O}$ que se torna central no processo de design é a experiência do usuário.

Portanto, existem muitos questionamentos a serem respondidos, como: sendo o design capaz de promover experiências, como seria possível trabalhar intencionalmente os possíveis efeitos de valor e afetividade, ou ainda, as possíveis reações resultantes do trabalho realizado pelo designer? Assim, entender o conceito de desejo permitirá uma análise mais assertiva de como ele se relaciona com o design. 


\title{
Coisa, objeto, artefato e desejo
}

Moles (2001) diz que "uma pedra é uma coisa, e se tornará objeto quando for promovida pela indústria humana das 'recordações' e 'lembranças' à dignidade de peso para papéis com uma etiqueta: preço, qualidade [...]" (MOLES, 2001, p. 33). Evoluindo este pensamento de Moles, esta mesma pedra que foi promovida a objeto apenas pelo simples fato de ter sido designado a ela uma função, se tornará um artefato quando altera-se qualquer elemento em sua estrutura original, seja uma textura, uma cor, uma base de vidro etc., demonstrando que a intervenção humana sobre qualquer objeto modifica a forma como é percebido, gerando significados que levam a provocação do desejo. Quando os designers trabalham com o desenvolvimento projetual a partir de um objeto existente, ainda que ele esteja apenas no campo imaginativo, eleva-se este objeto à categoria de artefato, além de possibilitar uma relação mais rica e proveitosa deste artefato com as pessoas e o ambiente que estará inserido.

Para Sudjic (2010) os designers contemporâneos devem lidar com várias definições de seu objetivo. O autor exemplifica quando se refere a um par de óculos que é tanto um utensílio de caráter medicinal quanto um acessório de moda, enfatizando que os óculos são uma espécie de joia, ou seja, modificam a aparência e, assim, a personalidade de quem os usa, mas ao mesmo tempo, as pessoas não querem que eles quebrem com facilidade ou lhes forcem a visão. Quando se compreende a linguagem do design, expressa por forma, cor, textura e imagem de um objeto, há constantes paradoxos entre função e simbolismo a ser considerados.

O design também pode aperfeiçoar simbolicamente os artefatos, incrementando-os com valores agregados ${ }^{2}$, ampliando a experiência sensorial através dos seus atributos (variáveis).

\begin{abstract}
O que sobra para um designer lidar é a superfície, a aparência e as nuances semânticas do significado que nos permitem interpretar e entender o que um objeto está tentando nos dizer sobre si mesmo. Essas mensagens vão desde o que um objeto faz, e quanto vale, até o modo de ligá-lo. São questões que estão longe de ser triviais, mas transformam o designer em narrador (SUDJIC, 2010, p. 34).
\end{abstract}

Considerando as diversas camadas de projeção do design, pode-se considerar que as características que tornariam o artefato desejável, ou seja, os mecanismos que poderiam acionar o despertar do desejo das pessoas sobre qualquer artefato, estariam entre as variáveis trabalhadas a partir do momento em que a coisa torna-se objeto, até a transformação em artefato a partir da manipulação das suas variáveis, relacionando-os ao pressuposto repertório e cultura do usuário.

\section{O exemplo de "Porca miséria"}

O lustre Porca Miséria criado pelo Lighting Designer alemão, Ingo Maurer (FIG. 3) é um exemplo de incrementação de valor simbólico produzido no desenvolvimento do artefato. Neste produto (artefato) em especial, Maurer traduziu uma experiência pessoal através da manipulação de variáveis em uma luminária na produção de novos significados, e foi essa manipulação intencional que gerou forma simbólicas que despertam o desejo das pessoas que o contemplam.

\footnotetext{
${ }^{2}$ Valor agregado é a formulação conceitual de um valor adicional, que adquirem os bens ou serviços quando são transformados, durante ou depois de seu processo produtivo - um valor simbólico.
} 
Figura 3 - Ingo Maurer e o lustro Porca Miséria

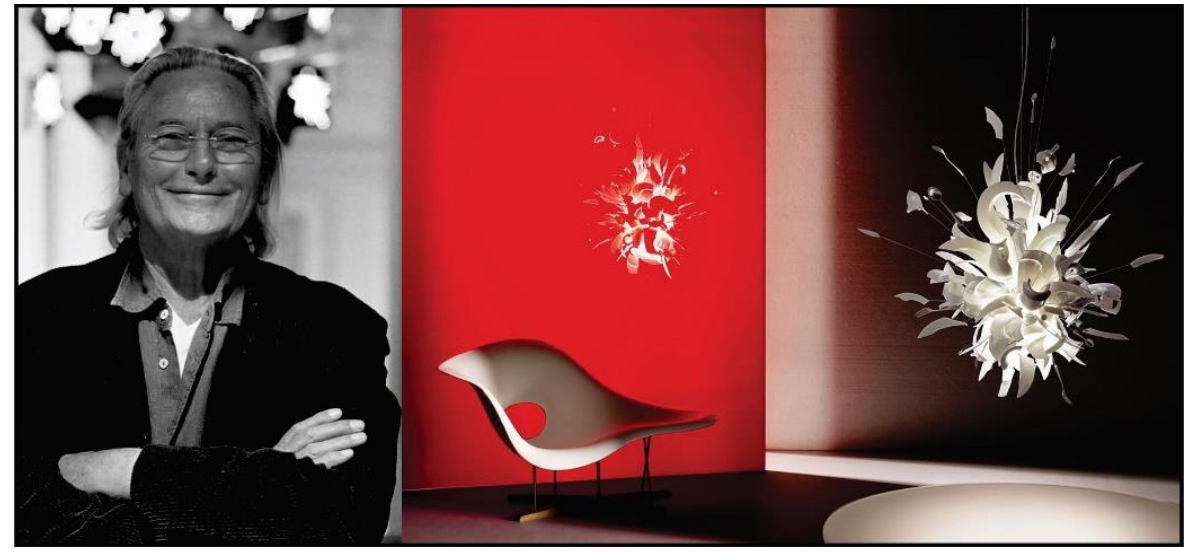

Fonte: https://www.ingo-maurer.com/en/products/porca-miseria

Schuster (2013) conta que, voltando de uma viagem à China, Maurer trazia no seu colo, durante todo o trajeto da viagem, uma caixa contendo um jogo de louças Chinesas. Ao se aproximar da entrada de sua casa, Maurer tropeçou num ressalto e deixou a caixa cair, transformando todas as louças em centenas de cacos de porcelana. Neste momento ele grita: "Porca Miséria", um termo italiano, usado quando se quer extravasar em uma situação ruim. Posteriormente, analisando com calma os cacos da porcelana, Maurer relacionou o ocorrido com uma explosão, mas foi além, porque seu pensamento de imediato fazia uma analogia entre o momento que antecede uma explosão, que é uma emissão grande de luz, associando à possibilidade da criação de um artefato que produza luz, ou seja, uma luminária. Mas para significar uma explosão no artefato, a luz teria que ser margeada pelos cacos, dando realmente a impressão de uma explosão no espaço infinito, próximo à ideia da teoria de criação do universo, o Big Bang.

Só é possível correlacionar à criação de Ingo Maurer neste caso, pois, no geral, as pessoas possuem como repertório de vida, na memória, registros imagéticos de explosões das mais variadas possíveis e, consequentemente, o voo alucinante de pedaços do que quer que seja para todos os lados. Neste momento, Maurer criou um artefato para iluminação artificial, dentro de um contexto espacial decorativo, mas fora dos padrões estéticos vigentes, fora da assimilação estético/formal de um objeto cuja função é iluminar, porque simplesmente ninguém tinha visto algo similar antes. Deste contexto, nasceu um dos produtos mais emblemáticos da marca Ingo Maurer, gerando uma forma simbólica a partir da transformação de um fato, ocorrido fora do seu controle, em conceito atribuído a um artefato. Na sequência, ele criou um novo objeto de desejo.

\section{Considerações finais}

O percurso da cultura do design possibilitou criar a hipótese de que toda esta construção significativa está inserida dentro de um processo evolutivo. Percebe-se esta cultura como um processo inserido numa espiral ascendente, que parte de um mesmo elemento impulsionador, mas que em cada volta completa que dá, sofre uma evolução, se alterando, se recompondo, se reconstruindo ou mesmo se ressignificando, gerando a possibilidade que o design do século XXI oferece aos seres humanos: a de receber algo que ainda não sabiam que iriam desejar. Esta pode ser a nova e revolucionária cultura do desejo que vem alterar a cultura do design deste século XXI e 
oferecer às pessoas mais do que uma estrutura física e funcional dos artefatos, mas elementos intangíveis, assumidos, interpretados e reinterpretados (ressignificados) pelas pessoas.

Acredita-se que esta nova cultura do desejo, que está relacionada diretamente aos artefatos, precisa de atenção especial, estudos e pesquisas, para que desta forma seja possível municiar os designers, e outros profissionais ligados direta ou indiretamente na produção de cultura material, com conhecimento e ferramentas que os auxiliem na articulação correta dos sistemas sígnicos no design.

\section{Referências}

DAVIS, Melinda. A nova cultura do desejo. Tradução Eliane Fraga e Sylvio Gonçalves. Rio de Janeiro: Record, 2003.

JORDAN, Patrick W. Designing pleasurable products: an introduction to the new human factors. London: CRC Press, 2003.

LACAN, J. O seminário: a transferência. Rio de Janeiro: Jorge Zahar Editor, 1992.

LIPOVETSKY, Gilles. A estetização do mundo: viver na era do capitalismo artista. São Paulo: Companhia das Letras, 2015.

O império do efêmero: a moda e seu destino nas sociedades modernas. São Paulo: Companhia das Letras, 2009.

MITCHELL, T. 1993. Redefining designing: From form to experience. New York, Van Nostrand Reinhold, 1993.

MOLES, Abraham. O kitsch. São Paulo: Perspectiva, 2001.

MOZOTA, Brigitte Borja de; KLÖPSCH, Cássia; COSTA, Filipe Campelo Xavier da. Gestão do design: usando o design para construir valor de marca e inovação corporativa. Porto Alegre: Bookman, 2011.

NORMAN, Donald A. Design emocional: por que adoramos (ou detestamos) os objetos do dia-a-dia. Tradução Ana Deiró. Rio de Janeiro: Rocco, 2008.

SANTAELLA, Lucia. A percepção: uma teoria semiótica. 2. ed. São Paulo: Experimento, 1998.

Semiótica aplicada. São Paulo: Cengage Learning, 2008.

SCALETSKY, Celso Carnos. Design estratégico em ação. São Leopoldo: Unisinos, 2016.

SCHUSTER, Julia. What porcelain is. A research about what porcelain is and can be, Published on ISSUU, Austrália, 2013

SUDJIC, Deyan. A linguagem das coisas. Tradução Adalgisa C. Silva. Rio de Janeiro: Intrínseca, 2010. VERGANTI, Roberto. Design-driven innovation: mudando as regras da competição - a inovação radical do significado de produtos. São Paulo: Canal Certo, 2012. 